\title{
Renal lithiasis from a nephrologist's perspective
}

\author{
Adelaide Serra, MD \\ Nephrology Department, Hospital Professor Doutor Fernando Fonseca, Amadora
}

\section{ABSTRACT}

Man has known urinary lithiasis since antiquity. In Portuguese medicine, this is a pathology seen predominantly from the urology perspective, but renal lithiasis is evaluated and treated preventively by nephrologists worldwide, and its study has contributed significantly to knowledge of how the renal tubule works. Nephrolithiasis is a relatively common disease in the adult population and, in Portugal, is observed in about $7.3 \%$ of the population.

The main pathophysiological mechanisms of the most frequent types of kidney stones and who and how to conduct the metabolic research are briefly described. Medical treatment is also addressed, keeping in mind that nephrolithiasis is often accompanied by extra-renal manifestations that should be investigated and treated, namely arterial hypertension, obesity, diabetes mellitus and osteo-metabolic disease.

\section{INTRODUCTION}

Man has known urinary lithiasis since antiquity, with the first stones identified in Egyptian mummies of about 8000 BC. The earliest written references on urinary lithiasis and its forms of treatment are placed between 3200 and 1200 BC, with lithotomy being described for the first time between $600 \mathrm{BC}$ and $600 \mathrm{BC}^{1}$.

In Portuguese medicine, this is a pathology seen predominantly from the urology perspective, but nephrolithiasis has always been studied and treated from a medical point of view. Currently, renal lithiasis is evaluated and treated preventively by nephrologists worldwide, and its study has contributed significantly to knowledge of how the renal tubule works. In the last decades, the contribution of urology to the treatment of nephrolithiasis, with the development of kidney stone destruction or removal techniques, has been extremely important in solving obstructive complications, with the contribution of the two specialties indispensable for the treatment and prevention of this pathology.

Nephrolithiasis is a relatively common disease in the adult population, with an overall prevalence in Western countries of $10 \%$ of the adult population ${ }^{2}$. In Portugal, according to Domingos $\mathrm{F}^{\text {et }} \mathrm{al}^{3}$, its prevalence is increasing, observed in about $7.3 \%$ of the population.

In recent decades, with industrialization and globalization, there has been a progressive increase in the incidence of nephrolithiasis in all Western countries. The causes for this increase seem to be related to the improved standards of living seen after World War $1 \mathrm{I}^{4}$.

The disease is known mainly for its most common clinical manifestation - renal colic - although in many cases there may be no symptoms, or minimal (calculi detected only at imaging or autopsy). It usually has a benign course but, when untreated (or incorrectly treated), recurrent nephrolithiasis is a chronic disease and may be responsible for significant morbidity, loss of working days, high social costs and loss of renal function. It is a cause of terminal chronic kidney disease in $5 \%$ of European patients in renal replacement therapy ${ }^{5,6}$.

Despite all the available scientific evidence, if we exclude the treatment of obstructive complications, no attempt is made to identify and correct the risk factors of the disease in the overwhelming majority of patients with nephrolithiasis. Preconceived ideas and lack of knowledge of valid scientific principles have generalized the adoption of incorrect recommendations and practices on the treatment of this disease.

\section{PATHOPHYSIOLOGY}

Urine is a solution normally supersaturated in crystallization promoters (calcium, urates, oxalate, phosphates). There are physicochemical conditions that can also favor the formation of stones, such as urinary $\mathrm{pH}$, the tubular flow rate of urine (urine output) or urinary stasis.

The renal tubule has important defense mechanisms against the formation of kidney stones (in its absence the formation of stones would be universal!). The most important factor is the presence in the urine of inhibitors of crystallization, aggregation, adhesion to the tubular epithelium and growth of the calculi: citrate, magnesium, pyrophosphate, Tamm-Horsfall protein (which, under certain physicochemical conditions, can function as a promoter crystallization) and other urinary macromolecules.

The formation of stones always represents an imbalance between promoters and crystallization inhibitors (supersaturation of urine in a certain salt) and / or alteration of the physicochemical conditions of urine (low volume or urinary stasis, urinary $\mathrm{pH}$ ). This change may be occasional (dietary excesses, prolonged periods of water deprivation, iatrogenic), or permanent as in patients with recurrent lithiasis. 
About $70-90 \%$ of the stones contain calcium, especially calcium oxalate, with cystine, struvite, or pure uric acid (UA) being rare.

The formation of crystal nuclei is usually heterogeneous, with a mixture of substances including uric acid. If nucleation occurs, conditions for crystal growth and subsequent aggregation are met, with formation of calculi that may be calcium oxalate, pure UA, struvite or other.

Regardless of the cause of renal lithiasis or the type of calculi, adequate urine output (greater than $2 \mathrm{~L} /$ day) reduces urinary supersaturation and contributes to the prevention of new stones.

Table 1 shows the urinary changes that may be present in each of the major types of kidney stones.

\section{Table 1}

Urinary changes present in the various types of calculi

\begin{tabular}{l|l}
\multicolumn{1}{c|}{ Type of calculi } & \multicolumn{1}{c}{ Urinary changes } \\
\hline Calcium oxalate & $\begin{array}{l}\text { Hyperoxaluria } \\
\text { Hypercalciuria } \\
\text { Hyperuricosuria } \\
\text { Hypomagnesuria } \\
\text { Hypocitraturia } \\
\text { Low urinary volume }\end{array}$ \\
& $\begin{array}{l}\text { Alkaline urine } \\
\text { Hypercalciuria } \\
\text { Calcium phosphate }\end{array}$ \\
& $\begin{array}{l}\text { Hersistently acidic urine } \\
\text { Low urinary volume } \\
\text { Hyperuricosuria }\end{array}$ \\
Uric acid & Infection with urease-producing bacteria \\
Struvite & $\begin{array}{l}\text { Poor cystine tubular reabsorption } \\
\text { Cystine }\end{array}$ \\
\hline
\end{tabular}

\section{Calcium oxalate}

The majority of patients with calcium oxalate stones have hypercalciuria (urinary excretion $>300 \mathrm{mg}$ / day in men and $>250 \mathrm{mg} /$ day in women, or $>4 \mathrm{mg} / \mathrm{kg}$ in both) (Table 2). Hypercalciuria may be idiopathic (most common, with a strong familial component) or may be due to renal tubular acidosis, primary hyperparathyroidism, sarcoidosis, excess vitamin D or glucocorticoids, hyperthyroidism or loop diuretics. It is also present when there is an increased intake (and consequent excretion) of sodium; sodium excretion correlates directly with calcium excretion, so it is not possible to correct hypercalciuria without sodium excretion being normalized.

Hyperoxaluria may result from increased intestinal oxalate uptake (increased ingestion or inflammatory conditions that facilitate the absorption of oxalate), or increased endogenous production of oxalate (a rare condition, responsible for primary hyperoxaluria). In the intestine, calcium works as a chelator of oxalate; in situations of malabsorption, the free fatty acids in the intestine increase, calcium binds to fatty acids and is no longer available to bind to the oxalate, which is free in greater amounts to be absorbed. For this reason, there is no advantage in systematically reducing calcium intake (except in situations of absorption hypercalciuria).
Hypocitraturia ( $<1.67 \mathrm{mmol} / 24 \mathrm{~h}$ or $320 \mathrm{mg} / 24 \mathrm{~h}$ ) is present mainly in inflammatory bowel diseases and renal tubular acidosis and is an important cause of renal lithiasis, since citrate is an important inhibitor of crystallization.

Hyperproteic and low carbohydrate diets produce a high acid load, increasing the risk of stone formation (decreased urinary $\mathrm{pH}$, decreased calcium balance) and loss of bone mass.

\section{Uric acid}

The formation of UA calculi depends more on urinary $\mathrm{pH}$ than on urinary excretion. Even if UA excretion and urinary volume are normal, supersaturation in UA is always high when urinary $\mathrm{pH}$ is less than 5.5 .

Calculi of UA are frequent in patients with metabolic syndrome (diabetes mellitus, hypertension, obesity and hypertriglyceridemia), probably due to a defect in ammonia production resulting from insulin resistance ${ }^{7}$ and consequent reduction in urinary $\mathrm{pH}$.

\section{Cystine}

Cystinuria is a relatively common, autosomal recessive genetic disorder that results in a change in the gastrointestinal and renal transport of cystine, ornithine, arginine, and lysine. Since cystine is insoluble in acid urine, it will precipitate and form kidney stones.

\section{Struvite}

Struvite calculi arise in situations of chronic upper urinary tract infections by urease producing bacteria: Proteus spp, Haemophilus spp, Klebsiella spp and Ureaplasma urealyticum. Urease promotes

\section{Table 2}

Measured urinary parameters

\begin{tabular}{l|l}
\multicolumn{1}{c|}{ Parameter } & \multicolumn{1}{c}{ Reference values } \\
\hline Calcium & $\begin{array}{l}\text { Female: }<6.25 \mathrm{mmol} / 24 \mathrm{~h}(250 \mathrm{mg} / 24 \mathrm{~h}) \\
\text { Male: }<7.5 \mathrm{mmol} / 24 \mathrm{~h}(300 \mathrm{mg} / 24 \mathrm{~h})\end{array}$ \\
Oxalate & $<0.5 \mathrm{mmol} / 24 \mathrm{~h}(45 \mathrm{mg} / 24 \mathrm{~h})$ \\
Uric acid & $<3.54 \mathrm{mmol} / 24 \mathrm{~h}(600 \mathrm{mg} / 24 \mathrm{~h})$ \\
Citrate & $>1.67 \mathrm{mmol} / 24 \mathrm{~h}(320 \mathrm{mg} / 24 \mathrm{~h})$ \\
pH & - \\
Volume & $>2 \mathrm{~L} / 24 \mathrm{~h}$ \\
Sodium & $<200 \mathrm{mEq} / 24 \mathrm{~h}$ \\
Potassium & $25-125 \mathrm{mEq} / 24 \mathrm{~h}$ \\
Phosphorus & $16-35,5 \mathrm{mmol} / 24 \mathrm{~h}(0.5-1.1 \mathrm{~g} / 24 \mathrm{~h})$ \\
Magnesium & $2.47-4.94 \mathrm{mmol} / 24 \mathrm{~h}(60-120 \mathrm{mg} / 24 \mathrm{~h})$ \\
Sulphate & $<25 \mathrm{mmol} / 24 \mathrm{~h}$ \\
Urea & Variable \\
Creatinine & Variable \\
Ammonia & $<40 \mathrm{mEq} / 24 \mathrm{~h}$ \\
Cystine & Negative in qualitative test \\
& $<280 \mu \mathrm{mol} / \mathrm{g}$ creatinine \\
\hline
\end{tabular}


the hydrolysis of urea, with the production of ammonia and, consequently, the creation of persistently alkaline urine that favors the formation of magnesium ammonium phosphate (struvite) stones. They are most often coraliform stones and occur mainly in women and in individuals with chronic obstructions of the urinary tract.

\section{METABOLIC EVALUATION}

The metabolic study of renal lithiasis is expensive and cumbersome, and is not indicated in all patients. Individuals with documented recurrent $(\geq 2)$ episodes of renal colic, or individuals with only one episode of renal colic (or even with asymptomatic renal lithiasis) but with family history of renal lithiasis, single kidney, inflammatory bowel disease, osteo-metabolic disease, recurrent urinary tract infections, uric gout, medullar sponge kidney or nephrocalcinosis, should be referred to the Nephrology-Renal Lithiasis clinic to perform a complete evaluation (Figure 1).

\section{Figure 1}

Metabolic evaluation

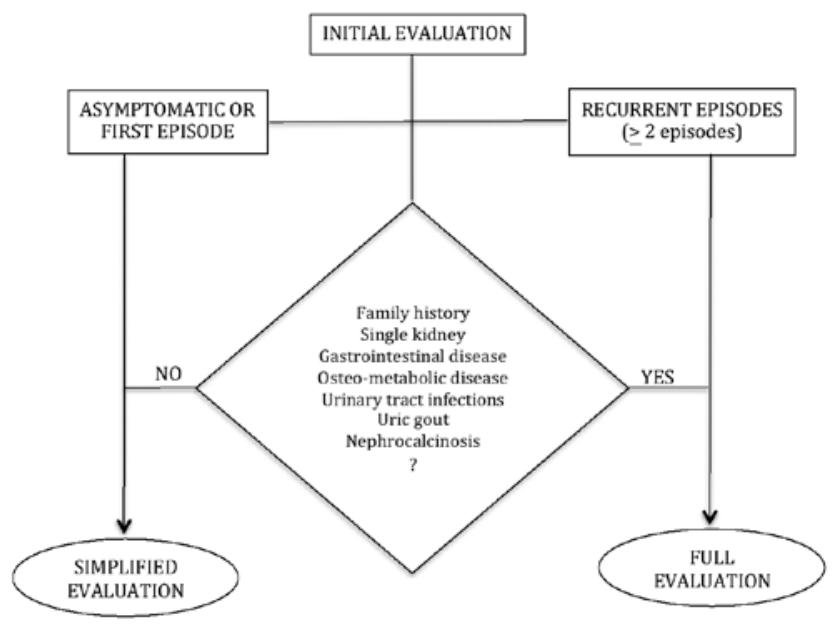

In the anamnesis, the number and periodicity of the episodes should be investigated, if there were previous treatments (and which) and possible complications, if there are concomitant pathologies or a family history of renal lithiasis. A small questionnaire on dietary habits, such as fluid intake, calcium intake, oxalates, salt and animal proteins, should be carried out. In usual medication, drugs such as calcium channel blockers, ascorbic acid, furosemide, calcium and / or vitamin $D$, antacids, uricosuric agents, triamterene or acetazolamide and theophylline should be investigated.

For individuals who are indicated for a more complete evaluation, blood and 24-hour urine collections should be performed. This study should not be performed less than 6 weeks after an episode of renal colic or urologic intervention on the urinary tract.
Biochemical analyses to identify patients with secondary causes of renal lithiasis include creatinine, calcium, phosphorus, uric acid, alkaline phosphatase, iPTH, sodium, potassium and chlorine. In 24-hour urine, calcium, oxalate, citrate, uric acid, magnesium, sodium, potassium, chlorine and cystine should be analysed. Urinary phosphate, urea and sulfate should be measured as indirect markers of protein consumption. Urinary volume should be quantified and urinary $\mathrm{pH}$ measured prior to the addition of any preservative into the urine. Urine creatinine is measured to evaluate the correction of urine collection, and a urine culture must be taken to exclude the presence of urinary tract infection. Whenever possible, fresh urine should be collected for crystaluria. When it is possible to obtain, renal calculi should be analysed, preferably by infrared spectrophotometry.

The imaging evaluation should always include a renal ultrasound, and a simple abdominal $X$ ray if the identified calculi are greater than $5 \mathrm{~mm}$. If there is clinical suspicion of medullar sponge kidney, presence of urinary malformations, obstruction or unilateral renal dysfunction, renal CT with contrast may be performed.

\section{MEDICAL TREATMENT}

Whatever the type of calculi, the first step in treating renal lithiasis is always a fluid intake that allows a diuresis of more than 2 liters.

Some dietary and pharmacological measures are suggested to control the most frequent types of kidney stones.

Calcium oxalate

- Hypercalciuria

- Diet: restriction of sodium intake and adequate intake of calcium (between 400-800 mg / day)

- Drugs: Thiazides (increases calcium reabsorption)

- Hyperoxaluria

- Diet: restriction of intake of oxalates (nuts, dark green vegetables, beets, citrus fruits, etc.)

- Drugs: do not supplement with vitamin C; in patients with enteral hyperoxaluria there may be a need for calcium supplements, which should be given during meals as oxalate chelators

- Hyperuricosuria

- Diet: restriction of animal protein

- Drugs: allopurinol

- Hypocitraturia

- Diet: increased consumption of vegetable fiber and fruit

- Drugs: potassium citrate

Uric acid

- Diet: restriction of the consumption of proteins (mainly animal)

- Drugs: potassium citrate for alkalinisation of urine; Allopurinol if serum uric acid $>8 \mathrm{mg} / \mathrm{dL}$ and / or urinary $>800 \mathrm{mg} / 24 \mathrm{~h}$

Cystine

- Diet: ingestion of liquids to obtain a diuresis of more than 3 liters 
- Drugs: potassium citrate for alkalinisation of urine; captopril, penicillamine if urinary cystine $>300 \mu \mathrm{mol} / \mathrm{g}$ creatinine (bind to cystine and form soluble complexes)

Struvite

- Diet: ingestion of liquids to obtain a diuresis of more than 2 liters

- Drugs: prolonged antibiotic therapy

- Removal of existing calculi

- Consider urine acidification (cranberry)

\section{MORBIDITY}

I cannot conclude without mentioning that in addition to renal complications related to repeated episodes of renal colic and urologic procedures and eventual loss of renal function, nephrolithiasis is often accompanied by extra-renal manifestations that should be investigated and treated, namely arterial hypertension, obesity, diabetes mellitus and osteo-metabolic disease.

\section{References}

1. Domingos F, Serra A. History of urinary lithiasis - the beginnings of nephrology. Rev Port Nefrol Hipert 2004; 18 (3): 143-153

2. Ramello A, Vitale C, Marangella M. Epidemiology of nephrolithiasis. J Nephrol 2000; 13 (3): S65-S70 Lonsdale K. Human stones. Science 1968; 159 (820): 1199-1207

3. Domingos F, Serra A. Nephrolithiasis is associated with an increased prevalence of cardiovascular disease. Nephrol Dial and Transplant 2011; 26 (3): 864-868

4. Goldfarb S. Dietary factors in the pathogenesis and prophylaxis of calcium nephrolithiasis. Kidney Int 1988; 34 (4): 544-555

5. Jungers $P$. Urolithiasis as a cause of end-stage renal failure: How can we prevent it? In: Jungers $P$, Daudon, M, editors. Renal Stone Disease: Proceedings of the 7th European Symposium on Urolithiasis; 1997 May; Paris. Paris: Elsevier; 1997. p. 251-257

6. Hobi Ch, Garzoni D, Ackermann D. The role of urolithiasis as a cause of chronic renal failure. In: Jungers P, Daudon, M, editors. Renal Stone Disease: Proceedings of the 7th European Symposium on Urolithiasis; 1997 May; Paris. Paris: Elsevier; 1997. p 262-263

7. Domingos F, Serra A. Metabolic syndrome: a multifaceted risk factor for kidney stones. Scand J Urol 2014 Oct; 48 (5): 414-419

\section{Correspondence to:}

M Adelaide Serra, MD

Nephrology Department, Hospital Professor Doutor Fernando Fonseca, Amadora E-mail: maria.a.serra@hff.min-saude.pt 